\title{
FAILURE OF HYPERIMMUNE GAMMA GLOBULIN TO PREVENT WHOOPING COUGH
}

\author{
BY \\ DAVID MORRIS* and J. C. MCDONALD \\ From Queen Elizabeth Hospital for Children, London, and the Epidemiological Research Laboratory, \\ Central Public Health Laboratory, Colindale
}

(RECEIVED FOR PUBLICATION NOVEMBER 27, 1956)

Whooping cough is still a major hazard of infancy. Immunization against it is increasingly practised, but is seldom begun before the sixth month, leaving the infant unprotected in the potentially dangerous first few months of life. It was with these facts in mind that we decided to investigate the effects of hyperimmune gamma globulin in the prevention of whooping cough.

Previous workers (McGuinness, Armstrong and Felton, 1944) had shown that large doses of hyperimmune serum were apparently effective in the prevention and treatment of pertussis and suggested that gamma globulin might be found more effective. Cruickshank (1949) reported that, in controlled trials in three residential nurseries, antiserum prepared in rabbits and horses temporarily protected most children inoculated in the incubation period. We present here the results of two controlled trials designed to evaluate two preparations of gamma globulin made from the blood of hyperimmunized donors in the protection of susceptible home contacts of whooping cough.

\section{Preparations under Trial}

In the first trial a special hyperimmune gamma globulin prepared by Cutter Laboratories, California, was matched against an inactive control inoculation. The Cutter product was described by the manufacturers as a refined globulin fraction from the blood of adults having a history of pertussis in childhood, hyperimmunized with Cutter phase 1 pertussis vaccine. The control inoculation was a $1.5 \%$ solution of autoclaved gelatin similar in appearance to the globulin solution and put up in identical ampoules. A $2.5 \mathrm{ml}$. dose of both preparations was used. Each $2.5 \mathrm{ml}$. dose of the globulin solution contained approximately $200 \mathrm{mg}$.

* In receipt of a research grant from the North Eastern Metropolitan Regional Hospital Board. of globulin obtained from about $25 \mathrm{ml}$. of human serum.

In the second trial gamma globulin prepared by Dr. M. E. Mackay at the Medical Research Council Blood Products Research Unit, Lister Institute, from the blood of hyperimmunized volunteer medical students was compared with gamma globulin prepared at the Lister Institute from the blood of normal adult donors. A $6 \mathrm{ml}$. dose of both preparations was used, each dose containing approximately $500 \mathrm{mg}$. of gamma globulin obtained from about $80 \mathrm{ml}$. of human serum. Both preparations were in similar containers. The medical students had been inoculated four times at monthly intervals with a pertussis vaccine made by the Michigan Department of Health, which was used as a reference vaccine in a recent Medical Research Council field trial and which was shown to protect children (Report, 1956). Some of the students had severe reactions, particularly after the second inoculation, and could not complete the course.

In both trials the preparations bore labels of identical appearance inscribed with a number from a random series to indicate the order in which they were to be used.

\section{Laboratory Tests}

Both hyperimmune gamma globulins were examined by Dr. Naomi Datta of the Standards Laboratory, Colindale, and Mr. A. F. B. Standfast of the Lister Institute. Dr. Datta tested the preparations during and after the clinical trials and reported Haemophilus pertussis agglutination titres of 1/1024 for Lister and Cutter products on each occasion. This may be compared with the following titres for eight batches of normal Lister gamma globulin taken at random: 1/32, 1/64, 1/128 (four batches) and 1/256 (two batches). Mr. Standfast, using the intracerebral mouse test (Report, 1956), examined 
the Lister hyperimmune gamma globulin, the plasma pool from which it was prepared and some hyperimmune rabbit serum before the clinical trials in 1953; he tested the Cutter hyperimmune gamma globulin, and these sera again, after the trials in 1956. He concluded from his results that the Lister gamma globulin was about twice as potent as the original plasma; that the Cutter and Lister products and the rabbit serum were of approximately equal potency; and that the Lister gamma globulin maintained its strength between 1953 and 1956.

\section{Method of Trial}

Healthy children under 5 years of age who had been in contact with other children with whooping cough in the same household were eligible for treatment provided they were symptomless, had no past history of the disease and had not been actively immunized against it. General practitioners and medical officers of health in certain London boroughs were asked to help in finding contacts meeting these requirements. Doctors were asked to inform us, if possible by telephone, of suitable families; these were visited without delay. The nature of the investigation was explained to parents and with their permission suitable contacts were inoculated. In the first trial the dose $(2.5 \mathrm{ml}$.) was given within 14 days after the onset of symptoms in the primary case. In the second trial the larger dose $(6 \mathrm{ml}$.) was given within 10 days after the onset in the primary case.

Inoculated children were observed for 28 days to find out if they developed whooping cough. Any child who developed a cough during this period was observed until his symptoms disappeared to determine the diagnosis, the duration and the severity of the attack. An attempt was made to take at least three pernasal swabs from every primary (infecting) case and from every treated contact who developed a cough. The swabs were taken at approximately three to four-day intervals as soon as possible after the onset of symptoms and sent at once either to the Central Public Health Laboratory, Colindale, or to the laboratory of the Queen Elizabeth Hospital for Children, London, where they were examined for the presence of Haemophilus pertussis. At the first follow-up visit, usually within 72 hours, a note was made of any inoculation reaction. No untoward reaction occurred in any of the children inoculated.

Details of the primary case and the contact child, together with the serial number of treatment given, the results of the follow-up and of the bacteriological findings were entered on a special record card for each family.

\section{Results}

The first trial ran from March to December, 1954. During this time 33 children were inoculated, 17 with hyperimmune gamma globulin (Cutter) and 16 with the control gelatin. In the treated group 10 developed a cough within 28 days and seven of these were classed as cases of moderate or severe whooping cough. In the control group seven developed a cough and four of these were thought to have moderate or severe whooping cough. When only those families were considered in which Haemophilus pertussis was isolated from either the infecting child or the contact it was found that seven out of 11 who received the hyperimmune gamma globulin developed moderate or severe whooping cough compared with four out of seven in the control group. As these figures did not suggest that the hyperimmune gamma globulin was having any protective effect it was decided to change to different preparations in larger dosage and to more stringent time requirements.

In the second trial, which ran from January to December, 1955 , only 17 children were treated, eight with hyperimmune gamma globulin (Lister) and nine with normal gamma globulin (Lister). Six of the eight and six of the nine developed a cough within 28 days. Five of those who had received the hyperimmune product were ranked as moderate or severe whooping cough and four of the other group were similarly assessed. Haemophilus pertussis was isolated in seven families given the hyperimmune gamma globulin and six families given normal gamma globulin. All the contacts that developed moderate or severe whooping cough were in these families. The total number of contacts treated in the second trial was admittedly small, but as suitable contacts were difficult to find and as there was no suggestion that the results were any better than in the first trial, it was decided to discontinue the investigation. The results of both trials are set out in the Table.

\section{Discussion}

Gamma globulin prepared from pooled adult serum or plasma has been shown to give passive protection against measles, infective hepatitis and poliomyelitis; the evidence for prophylaxis against rubella is less certain. In mumps and chickenpox reports suggest that this type of gamma globulin is ineffective. The findings of McGuinness et al. (1944) suggested that whooping cough contacts could be passively protected with hyperimmune serum. It was hoped that gamma globulin prepared from hyperimmune serum might also prove effective, but our findings do not confirm this. 
TABLE 1

RESULT OF TWO CONTROLLED TRIALS OF HYPERIMMUNE GAMMA GLOBULIN IN PREVENTION OF WHOOPING COUGH IN FAMILY CONTACTS UNDER 5 YEARS OF AGE

\begin{tabular}{|c|c|c|c|c|c|}
\hline Trial & Treatment & $\begin{array}{c}\text { Bacteriological Evidence } \\
\text { of Whooping Cough in } \\
\text { Family }\end{array}$ & $\begin{array}{c}\text { No. } \\
\text { Inoculated }\end{array}$ & $\begin{array}{l}\text { No. Developing Cough } \\
\text { Within } 28 \text { Days of } \\
\text { Inoculation }\end{array}$ & $\begin{array}{l}\text { No. with Moderate } \\
\text { or Severe Whooping } \\
\text { Cough }\end{array}$ \\
\hline I & $\begin{array}{l}\text { Hyperimmune } \\
\text { gamma globulin } \\
\text { (Cutter) }\end{array}$ & $\frac{+}{\text { total }}$ & $\begin{array}{r}11 \\
6 \\
17\end{array}$ & $\begin{array}{r}9 \\
1 \\
10\end{array}$ & $\begin{array}{l}7 \\
\mathbf{0} \\
\mathbf{7}\end{array}$ \\
\hline (Dose $2.5 \mathrm{ml}$.) & Control & $\frac{+}{-}$ & $\begin{array}{r}7 \\
9 \\
16\end{array}$ & $\begin{array}{l}5 \\
2 \\
7\end{array}$ & $\begin{array}{l}4 \\
0 \\
4\end{array}$ \\
\hline \multirow[b]{2}{*}{ (Dose $6 \mathrm{ml}$.) } & $\begin{array}{l}\text { Hyperimmune } \\
\text { gamma globulin } \\
\text { (Lister) }\end{array}$ & $\frac{+}{\text { total }}$ & $\begin{array}{l}7 \\
1 \\
8\end{array}$ & $\begin{array}{l}6 \\
0 \\
6\end{array}$ & $\begin{array}{l}5 \\
0 \\
5\end{array}$ \\
\hline & $\begin{array}{l}\text { Normal } \\
\text { gamma globulin } \\
\text { (Lister) }\end{array}$ & $\frac{+}{-}$ & $\begin{array}{l}6 \\
3 \\
9\end{array}$ & $\begin{array}{l}5 \\
1 \\
6\end{array}$ & $\begin{array}{l}4 \\
0 \\
4\end{array}$ \\
\hline \multirow[t]{2}{*}{$\begin{array}{l}\text { I and II } \\
\text { Combined }\end{array}$} & $\begin{array}{l}\text { Hyperimmune } \\
\text { gamma globulin }\end{array}$ & $\frac{+}{-}$ & $\begin{array}{r}18 \\
7 \\
25\end{array}$ & $\begin{array}{r}15 \\
1 \\
16\end{array}$ & $\begin{array}{r}12 \\
0 \\
12\end{array}$ \\
\hline & $\begin{array}{l}\text { Normal } \\
\text { gamma globulin } \\
\text { or control }\end{array}$ & $\frac{+}{\text { total }}$ & $\begin{array}{l}13 \\
12 \\
25\end{array}$ & $\begin{array}{r}10 \\
3 \\
13\end{array}$ & $\begin{array}{l}8 \\
0 \\
8\end{array}$ \\
\hline
\end{tabular}

As the dosage used in the first trial might have been too small it was doubled in the second, but no better results were obtained either in the prevention or in attenuation of the disease. It is possible that a still larger dose might give protection. In the first trial all inoculations were given within 14 days of onset of illness in the primary infecting case but in only seven out of 33 was the interval less than one week. In the second trial all 17 were injected within 10 days of onset but only five were in the first week. Thus in spite of every effort most inoculations were given late in the incubation period. This factor may have contributed to the unsuccessful result but in practice it seems unlikely that contacts could be inoculated much earlier.

Although both hyperimmune gamma globulins contained agglutinating antibody in high titre it does not follow that the factor responsible for protection was also present. Hink and Johnson (1950) showed that in mouse tests the protective antibody was located almost entirely in the $\gamma_{2}$-globulin fraction but only a minor portion of pertussis agglutinins could be recovered from this fraction. Both the Cutter product prepared by Cohn's method and the Lister product prepared by the method of Kekwick and Mackay (1954) consist mainly of $\gamma_{2}$-globulin and would therefore be expected to contain the protective antibodies for the mouse and this was confirmed in laboratory experiments. The intracerebral mouse test has shown some correlation with field trial results of pertussis vaccine (Report, 1956) but it may not be equally useful in the evaluation of sera used for passive immunization. However, even an effective passive immunizing agent could not be expected to protect unless given in time and in sufficient dosage. Nevertheless, our results suggest that hyperimmune gamma globulin in the doses used has at present no value in the prevention of whooping cough.

The management of susceptible children exposed to whooping cough remains a serious problem. Active immunization may be effective even when given as early as 3 months of age (Butler, 1954). Isolation of children suspected to be suffering from whooping cough is still all important, but, should the child in contact with whooping cough develop symptoms, then chloramphenicol or chlortetracycline may reduce the severity and the frequency of the paroxysms (Reports, 1953; Morris and Cockburn, 1954). As these drugs are not without danger suitable children should be carefully selected.

\section{Summary}

In two controlled trials 50 family contacts of whooping cough aged less than 5 years were injected with either gamma globulin prepared from the blood of donors hyperimmunized with a pertussis vaccine or with normal gamma globulin or an inactive inoculum (autoclaved gelatin). No evidence was found that hyperimmune gamma globulin reduced either the attack rate or the severity of whooping cough in the contacts.

We should like to thank the following for help in this investigation: Cutter Laboratories and Dr. M. E. Mackay, of the Lister Institute, for supplying the trial preparations, Professor R. Cruickshank and volunteer 
students of St. Mary's Hospital, London, for hyperimmune plasma, Dr. Naomi Datta, Dr. H. D. Holt, Dr. B. Levin and Mr. A. F. B. Standfast for laboratory work, general practitioners and medical officers of health who told us of whooping cough contacts, and Dr. W. Chas. Cockburn for advice and help.

\section{REFERENCES}

Butler, N. R. (1954). Proc. roy. Soc. Med., 47, 357.

Cruickshank, R. (1949). Fourth International Congress for Microbiology, Copenhagen, July 20-26, 1947. Report of Proceedings. Copenhagen, Rosenkilde and Bagger. p. 184.
Hink, J. H. Jr. and Johnson, F. F. (1950). J. Immunol., 64, 39.

Kekwick, R. A. and Mackay, M. E. (1954). Spec. Rep. med. Res. Coun. (Lond.), No. 286.

McGuinness, A. C. Armstrong, J. G. and Felton, H. M. (1944). J. Pediat., 24, 249.

Morris, D. and Cockburn, W. C. (1954). Lancet, 2, 724.

Report (1953) by the Whooping-Cough Subcommittee of the Antibiotics Clinical Trials. (Non-Tuberculous Conditions) Committee of the Medical Research Council. Lancet, 1, 1109.

Report (1956) to the Whooping-Cough Immunization Committee of the Medical Research Council and to the medical officers of health for Cardiff, Leeds, Leyton, Manchester, Middlesex, Oxford, Poole, Tottenham, Walthamstow and Wembley. Brit. med. J., 2, 454 . 